\title{
Conservation by Algorithm
}

William M. Adams

Digital devices are spreading rapidly in conservation as costs shrink and capabilities grow. They are changing the way conservation operates (Arts et al., 2015). To take just one example, the website of a wildlife concession in Tanzania recently described the use of a reconnaissance drone with photographic recognition software (Singita Grumeti Fund, 2017). The drone is programmed to fly pre-set grids across the concession. Video is processed by computer, using software to identify and locate potential 'threats' ('poachers and cattle'), distinguishing them from what the website bizarrely calls 'naturally occurring objects like wildlife'. If a potential threat is recognized, a short video clip is automatically flagged for the attention of the 'ops room technician' who reviews the forage and verifies. The 'threat' is then automatically entered into a 'Domain Awareness System'. In 'realtime', what are described as 'law enforcement assets' are then dispatched to deal with the problem.

This description is remarkable in many ways. One is obviously the social implications of the use of drones in conservation surveillance (Humle et al., 2014; Sandbrook, 2015). But I want to draw attention to another matter that is central to this story of automation. Digital technologies not only make it possible to fly unmanned surveillance, they also make it possible to process those data fast and automatically. The 'assets' that pour forth to counter marauding cows or people may be human, but those threats are identified by a computer.

This is an example of what I call 'conservation by algorithm' (Adams, 2017b), by which I mean the automation of conservation decisions using digital technology. It is an increasingly common part of conservation's normal operating procedures. I suggest it has three radical implications for conservation.

Firstly, the automation of field collection of biological data bypasses and reduces the need for skilled field workers. Mobile devices enable rapid capture of GPS and timestamped data that can be automatically uploaded via the web or phone system to a database. Numerous apps support citizen science initiatives (Jepson \& Ladle, 2015), and automated feedback can improve data quality (Van der Wal et al., 2016). Fixed and mobile digital sensors can generate continuous data within and beyond human capacities (e.g. ultrasound and infra-red; Arts et al., 2015), and survey remote regions far beyond human capability (e.g. GPS loggers on wandering albatrosses, enlisting the birds as surveyors to record radar emissions from fishing vessels; Weimerskirch

William M. Adams Department of Geography, University of Cambridge, Cambridge, UK.

E-mail wa12@cam.ac.uk et al., 2017). Digital sensors never tire, need no lunch breaks and belong to no unions. They do need batteries, but the cost and weight of these are falling rapidly. Digital data collection is widely heralded for its efficiency (Arts et al., 2015), but data are no longer contained within notebooks or on maps, contextualized by the experience of field surveyors. The rise of automation separates data from the human observation and skill in which it was once enmeshed.

Secondly, as knowledge is abstracted and standardized the nature of conservation expertise changes. Data volumes and rate of capture demand profound changes in traditional forms of data storage, exchange and-above all-analysis. Automated data cleaning and checking, using modelling techniques from engineering and computer science, are central to the search for quality control in ecological informatics (Porter et al., 2012). Algorithms promise radical improvements in analytical efficiency, such as reducing staffing costs by automated image processing of camera trap images (Price-Tack et al., 2016), and open up new analytical possibilities, such as the automated identification of individual tigers from stripe patterns ( $\mathrm{Yu}$ et al., 2013) and linking thermal, acoustic and ultrasound sensors in real time to reduce wind turbine mortality of bats and birds by feathering blades (Robinson Willmott et al., 2015). In algorithmic conservation, knowledge is held in databases that are the preserve of the analyst and programmer, who may never have seen where the information was collected.

The third radical implication of conservation by algorithm is the way it can generate conservation options and policy prescriptions. The combination of remote sensing data, machine-based mapping and spatial analysis are fundamental to the power of spatial conservation planning. Thus site selection and decision-support algorithms can be deployed to select protected areas, to maximize conservation at least cost (Fajardo et al., 2014), and law enforcement effort can be targeted, analysing the distribution of illegal activities (Plumptre et al., 2014). Of course, decision-support tools are, by definition, only supposed to support human decision-making. Yet automation is growing, and automated or semi-automated tools are increasingly mainstream. The deployment of such tools inevitably moves conservation decisions away from people affected by them and into the hands of remote decision-makers, or the technicians who devise the algorithms on which the tools rely.

In conservation and related sciences digital technologies are almost always seen as positive, generating novel and more voluminous data and analyzing them more rapidly and cheaply (Arts et al., 2015). My concern is that digital 
databases and the algorithms used to analyze them are black boxes, whose working is not transparent. Like Google and the other new global information corporations, conservation by algorithm promises quick, cheap and clever solutions to complex problems. But it does not offer to explain what happens in the box.

The most disturbing reliance on algorithms in conservation lies where I started, with drone surveillance of poachers. The risks of 'conservation by fear' have been pointed out (Humle et al., 2014). The technology has a disturbing genealogy. The term 'conservation by algorithm' is copied from military drone use in the Middle East in what Amoore (2009) calls 'algorithmic war'. Automated software systems link live remote sensing imagery with other sources of data or intelligence to identify bombing targets (Allinson, 2015). Of course, people are not yet absent from the chain (although there are frightening prospects of artificial intelligence in robotic warfare; Gibbs, 2017). Military drones have a 'pilot', viewing video streams and controlling plane and weapons from a computer suite far away. The traumatic stress of such roles, intimate and yet remote from the deaths they cause, is very real (brilliantly evoked in the novel I Saw a Man; Sheers, 2015). It is a disturbing possibility that as conservation is drawn into wider securitization agendas (Büscher \& Ramutsindela, 2015; Duffy, 2016), it could come to adopt the methods of algorithmic war.

Conservation by algorithm is undoubtedly here to stay. It involves everything from the apparently benign (exciting new scientific insights) to the profoundly scary (securitization). But both dimensions raise important questions about whom conservation is for, and who is, and should be, making decisions.

Technology is expensive and programming is specialized. Conservation by algorithm therefore has a tendency to move the power to direct conservation policy into the places where data is managed, where its analysis is understood, and the results can be debated among experts. This places conservation decisions in academic laboratories and the offices of governmental, non-governmental and for profit organisations. This is a recipe for 'conservation from above' (Adams, 2017a).

Conservation by algorithm is powerful, but without involvement of people on the ground it is unlikely that solutions identified by algorithm will work. The fieldworker who makes ecological observations, the farmer or hunter who knows how the seasons change, the water collector or firewood gatherer, are all essential to intelligent conservation solutions. Effective conservation grows from the engagement of human minds and hands (Smith et al., 2009). However impatient we are, we have to accept that there really isn't an app for that.

\section{References}

Adams, W.M. (2017a) Conservation from above: globalising care for nature. In The Anthropology of Sustainability (eds
M. Brightman \& J. Lewis), pp. 111-126. Palgrave Macmillan, New York, USA.

Adams, W.M. (2017b) Geographies of conservation II: technology, surveillance and conservation by algorithm. Progress in Human Geography. Https://dx.doi.org/10.1177/0309132517740220.

Allinson, J. (2015) The necropolitics of drones. International Political Sociology, 9, 113-127.

Amoore, L. (2009) Algorithmic war: everyday geographies of the war on terror. Antipode, 41, 49-69.

Arts, K., VAn Der Wal, R. \& Adams, W.M. (2015) Digital technology and the conservation of nature. Ambio, 44, 661-673.

Búscher, B. \& Ramutsindela, M. (2015) Green violence: rhino poaching and the war to save southern Africa's Peace Parks. African Affairs, 115, 1-22.

DufFy, R. (2016) War, by conservation. Geoforum, 69, 238-248.

Fajardo, J., Lessmann, J., Bonaccorso, E., Devenish, C. \& Muñoz, J. (2014) Combined use of systematic conservation planning, species distribution modelling, and connectivity analysis reveals severe conservation gaps in a megadiverse country (Peru). PLoS ONE 9(12): e114367.

GiBBs, S. (2017) Elon Musk leads 116 experts calling for outright ban of killer robots. The Guardian, 20 August. Https://www.theguardian. com/technology/2017/aug/20/elon-musk-killer-robots-expertsoutright-ban-lethal-autonomous-weapons-war [accessed 28 October 2017].

Humle, T., Duffy, R., Roberts, D.L., Sandbrook, C., St John, F.A.V. \& S MiTH, R.J. (2014) Biology's drones: undermined by fear. Science, $344,1351$.

JEPSON, P. \& LADLE, R. (2015) Nature apps: waiting for the revolution. Ambio, 44, 827-832.

Plumptre, A.J., Fuller, R.A., Rwetsiba, A., Wanyama, F., Kujirakninja, D., Driciru, M. et al. (2014) Efficiently targeting resources to deter illegal activities in protected areas. Journal of Applied Ecology, 51, 714-725.

Porter, J., Hanson, P. \& Lin, C. (2012) Staying afloat in the sensor data deluge. Trends in Ecology and Evolution, 27, 121-129.

Price-Tack, J.L., West, B.S., McGowan, C.P., Ditchkoff, S.S., Reeves, S.J., Keever, A.G. \& Granc, J.B. (2016) AnimalFinder: a semi-automated system for animal detection in time-lapse camera trap images. Ecological Informatics, 35, 145-151.

Robinson Willmott, J., Forcey, G.M. \& Hooton, L.A. (2015) Developing an automated risk management tool to minimize bird and bat mortality at wind facilities. Ambio, 44, 557-571.

SANDBRook, C. (2015) The social implications of using drones for biodiversity conservation. Ambio, 636-647.

Sheers, O. (2015) I Saw a Man. Faber and Faber, London, UK.

Singita Grumeti Fund (2017) Reconnaisance Drone Programme. Http://www.singitagrumetifund.org/our-work/special-projects/ \#reconnaissance-drones-project [accessed 27 October 2017].

Smith, R.J., Veríssimo, D., Leader-Williams, N., Cowling, R.M. \& KNight, A.T. (2009) Let the locals lead. Nature, 462, 280-281.

Van der Wal, R., Sharma, N., Mellish, C., Robinson, A. \& Siddharthan, A. (2016) The role of automated feedback in training and retaining biological recorders for citizen science. Conservation Biology, 30, 550-561.

Weimerskirch, H., Filippi, D.P., Collet, J., Waugh, S.M. \& PATRICK, S.C. (2017) Use of radar detectors to track attendance of albatrosses at fishing vessels. Conservation Biology. Http://dx.doi. org/10.1111/cobi.12965.

Yu, X., Wang, J., Kays, R., Jansen, P.A., Wang, T. \& Huang, T. (2013) Automated identification of animal species in camera trap images. EURASIP Journal on Image and Video Processing, 2013: 52. 